\title{
Múltiplas coisas ou Coisas Múltiplas? - Dois sentidos para o Paradoxo de Zenão no Parmênides de Platão
}

\author{
Many things or Multiple things? - Two Senses for Zeno's Paradox in Plato's \\ "Parmenides"
}

\section{Renato Matoso ${ }^{\mathrm{I}}$}

\begin{abstract}
Resumo: Neste artigo, examino a duplicidade de sentidos que a tese pluralista "os seres são

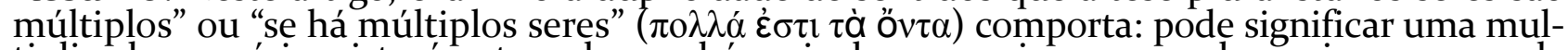
tiplicade numérica, isto é: a tese de que há mais de uma coisa no mundo, assim como pode significar que uma mesma coisa possui mais de um atributo. Incialmente, argumento que Socrates estava consciente desta ambiguidade, pois as duas compreensões de pluralismo representam perspectivas complementares de uma mesma posição filosófica. Segundo minha interpretação, o reconhecimento dessa ambiguidade permite melhor entender a crítica de Sócrates ao monismo eleático, sua defesa da Teoria das Ideias e sua distinção entre Formas transcendentes e propriedades imanentes. Estes dois sentidos de multiplicidade farão ainda parte da estratégia utilizada por Parmênides na sua contra-argumentação à solução socrática ao paradoxo de Zenão.
\end{abstract}

Palavras-chave: Monismo eleático; Pluralismo numérico; Pluralismo de atributos; Formas

Abstract: In this paper, I propose an original interpretation for the duplicity of meanings that the pluralistic thesis ( $\pi 0 \lambda \lambda \dot{\alpha} \dot{\varepsilon} \sigma \tau \imath \tau \dot{\alpha}$ őv $\tau \alpha$ ) comprises: it can mean a numerical multiplicity, that is: the thesis that there is more than one thing in the world, as well as can mean that the same thing has more than one attribute. Here it is argued that Socrates was aware of this ambiguity, and that these two understandings of pluratism represent complementary perspectives on the same philosophical position. This interpretation allows me to better understand Socrates' criticism against the Eleatic monism, and his distinction between Forms and immanent properties. Finally, I demonstrate how these two meanings of multiplicity are also part of the strategy used by Parmenides in his counter-argument to the Socratic solution to Zeno's paradox.

Keywords: Eleatic monism; Numerical pluralism; Attribute pluralism; Forms

O Parmênides descreve um diálogo travado entre Sócrates, ainda bastante jovem, Zenão, Parmênides e Aristóteles, não o filósofo, mas um jovem que viria a se tornar um dos trinta tiranos. A conversa que nos chega não é narrada por um dos presentes no encontro, mas por Céfalo que o tinha ouvido de Antifonte, meio irmão de Platão, que havia ouvido e memorizado a conversa a partir do relato de Pitodoro. Pitodoro, por sua vez, havia ouvido a conversa por ser companheiro de Zenão e ter abrigado os visitantes durante sua estada em Atenas (Alcib.I. 119a). Apesar de não ser o único diálogo a apresentar este tipo de encadeamento narrativo ${ }^{1}$, o Parmênides é o diálogo no qual o relato que nos é oferecido está mais distante da conversa original, tanto no tempo quanto no número de "elos" da cadeia narrativa. Afinal, aquele que lê o Parmênides (e, portanto, "ouve" a narrativa de Céfalo) encontra-se no quarto estágio de uma cadeia de transmissão do conteúdo de uma conversa

\footnotetext{
${ }^{1}$ O Fédon, o Banquete e o Teeteto também são narrados por pessoas que não presenciaram os acontecimentos descritos.
} 
que teria acontecido há, pelo menos, cinquenta anos antes do momento dramático em que Céfalo oferece seu relato ${ }^{2}$. A estrutura narrativa descrita no prólogo do Parmênides pode ser representada pela seguinte figura:

\section{[ZENÃO / PARMÊNIDES / SÓCRATES / ARISTÓTELES] \\ [PITODORO / ANTIFONTE] \\ [ANTIFONTE / CÉFALO] \\ [CÉFALO / LEITOR]}

Deste modo, o Parmênides relata uma conversa travada entre Zenão, Parmênides, Sócrates e Aristóteles, que foi narrada por Pitodoro a Antifonte, que narrou a mesma conversa a Céfalo, que, por sua vez, narra ao leitor. Este fato nos é lembrado em, pelo menos, duas passagens do texto, nas quais a cadeia de transmissão é explicitada (130a e 136e). Além disso, essa estrutura nunca desaparece plenamente de vista para o leitor do texto grego, pois todo o diálogo é em forma de discurso indireto, com discursos diretos inseridos. É claro, portanto, que tamanha complexidade de estrutura narrativa não pode ser acidental. Platão certamente intencionava passar alguma mensagem por meio da apresentação de um prólogo tão cuidadosamente construído e é tarefa do intérprete levantar hipóteses acerca destas intenções.

Como a maior parte dos comentadores observa, a primeira lição que podemos tirar da estrutura narrativa do Parmênides diz respeito à ausência total de veracidade histórica do relato. Ao estabelecer uma longa distância temporal entre a narrativa que nos é oferecida e o fato dramático que nos é narrado, Platão indica ao leitor que o conteúdo do Parmênides é plenamente ficcional e que ninguém deve tentar confirmar nenhum dos seus detalhes, mesmo que um encontro entre Parmênides e Sócrates tenha de fato acontecido, coisa que a maior parte dos comentadores considera improvável ou mesmo impossível ${ }^{3}$.

A segunda conclusão que podemos extrair da complexa estrutura narrativa apresentada no Parmênides diz respeito ao efeito dramático que este tipo de prólogo pretende criar no leitor. Nosso diálogo se inicia com a história de que, cinquenta anos após um encontro entre Parmênides, Zenão e Sócrates, um grupo de pessoas "bastante interessadas em

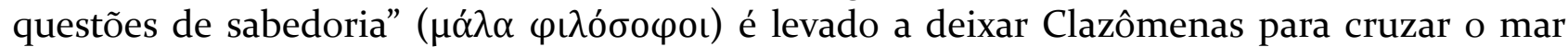
Egeu em busca de um ateniense que acreditam ter informações sobre o que teria se passado nesta reunião. Este ateniense, apesar de não haver estado presente no encontro, ocorrido

\footnotetext{
${ }^{2}$ A data dramática para a realização do suposto encontro entre Parmênides, Sócrates e Zenão é estabelecida pela menção às Grande Panatenéias, festivais realizados de quatro em quatro anos em honra a Atená. Segundo o diálogo, Parmênides e Zenão estariam em visita a Atenas com o objetivo de participar deste festival. De acordo com as informações que nos são fornecidas acerca da idade dos personagens do diálogo (127b-c: Parmênides teria por volta de sessenta e cinco anos, Zenão estaria próximo dos quarenta e Sócrates era ainda bastante jovem) podemos estabelecer o festival do ano de 449/450 a.C. como a data base para o encontro narrado. Como Céfalo não busca o próprio Sócrates para ouvir o relato deste encontro, podemos deduzir, ainda, que no momento da chegada de Céfalo e sua comitiva em Atenas, Sócrates já havia sido executado, fato ocorrido em 399 a.C. Sendo assim, ao menos cinquenta anos separam o relato de Antifonte do momento do encontro inicial. Não temos razão para acreditar que o relato de Céfalo esteja ocorrendo muito depois desta data, mas as indicações são precisas o suficiente para deixar claro ao leitor a considerável distância entre a narrativa que nos chega e a conversa original.

${ }^{3}$ A ausência de pretensão histórica é notada por praticamente todos os comentadores recentes. Mansfeld, adotando 462/461 como data dramática para o suposto encontro entre Parmênides e Sócrates, acredita, ainda, que este evento nunca poderia ter acontecido como descrito por Platão, pois, nesta data, Sócrates teria apenas oito anos de idade. "Nem ao menos se espera que os leitores do Parmênides acreditem que o encontro tenha realmente ocorrido..." (MANSFELD, Die Vorsokratiker, I: Milesier, Pythagoreer, Xenophanes, Heraklit, Parmenides, p. 44).
} 
antes mesmo de seu nascimento, considerava o conteúdo da conversa ali desenrolada tão importante que decidiu dedicar-se a decorá-la durante sua juventude. A pessoa de quem este ateniense ouviu a história, Pitodoro, tampouco participou ativamente da conversa, porém igualmente decorou o conteúdo do diálogo e passou adiante ${ }^{4}$.

O prólogo do Parmênides nos gera, assim, uma sensação de curiosidade acerca do texto que estamos prestes a ter acesso. Além disso, a longa lista de pessoas dedicadas à preservação do conteúdo desta conversa, assim como a longa jornada de Céfalo e seus companheiros em busca desta narrativa, nos garante a seriedade e a importância daquilo que nos será revelado. Como observa Allen, "a própria introdução do Parmênides, por si só, nos proíbe tratar o diálogo como um tipo estranho de piada ou trivializar o diálogo como uma mera ginástica ou um exercício de detecção de simples falácias"5. O prólogo do Parmênides adverte o leitor a se preparar, desde o início, para a profundidade e relevância do conteúdo que será apresentado.

A característica mais importante da abertura de nosso diálogo, no entanto, parece ter passado despercebida para maior parte dos comentadores. Trata-se do fato de que a complexa estrutura narrativa montada no prólogo do Parmênides encontra-se refletida na estrutura argumentativa do diálogo. Diferente da maior parte dos diálogos, nos quais um mesmo interlocutor expõe suas teses ou conduz a refutação de outro(s) personagem(ns), o Parmênides é constituído por uma série de momentos argumentativos distintos. Nosso diálogo começa com a leitura dos argumentos de Zenão e uma menção aos detratores de Parmênides, contra quem estes argumentos são endereçados. Logo em seguida, Sócrates aparece em cena e passa a argumentar contra Zenão. Por fim, Parmênides entra na discussão e passa a apresentar argumentos contra Sócrates. Desta maneira, temos Parmênides oferecendo críticas à Teoria das Ideias de Sócrates, que havia sido apresentada como uma refutação à argumentação de Zenão, que, por sua vez, havia sido apresentada como uma crítica à tese pluralista, defendida pelos detratores de Parmênides. Esta estrutura argumentativa pode ser representada pelo seguinte esquema:

[ PARMÊNIDES / PLURALISTAS]

[ PLURALISTAS / ZENÃO]

[ ZENÃO / SÓCRATES]

[SÓCRATES / PARMÊNIDES]

Da mesma forma que nossa história é narrada por uma pessoa que conta o que lhe foi narrado por outra pessoa, que contou o que lhe foi narrado por outra, os argumentos do diálogo são ordenados de tal modo que cada um deles remete aos resultados alcançados pelos argumentos precedentes, ao mesmo tempo em que fornece a base para o argumento que se seguirá. A estrutura argumentativa do Parmênides encontra-se, assim, refletida e prenunciada na estrutura narrativa descrita no prólogo do diálogo.

\footnotetext{
${ }^{4}$ É importante notar que, no momento em que Céfalo chega à Atenas em busca de informações sobre o encontro de Sócrates, Zenão e Parmênides, todas as pessoas que estavam presentes neste encontro já estão mortas, incluindo o próprio Sócrates. Portanto, para Antifonte e Céfalo, assim como para o leitor do diálogo, o Parmênides narra momentos da vida de figuras de uma geração passada, uma geração de grande importância para a comunidade filosófica grega, cujas conversas e debates merecem ser lembrados e revividos meio século após seu acontecimento. O prólogo do Parmênides presta, assim, uma homenagem a esta geração de pensadores já perdida e o fato de Platão fazer com que vários personagens tenham se dedicado ao ato de memorizar o conteúdo de um encontro entre estas pessoas indica, ainda, o apreço de Platão por estes indivíduos.

5 ALLEN, Plato's “Parmenides”, p.71.
} 


\section{O paradoxo de Zenão}

O primeiro argumento apresentado ao leitor do Parmênides é atribuído a Zenão. Como sabemos, Zenão foi um defensor do monismo eleata e seus argumentos receberam muito prestígio, ainda na antiguidade. $O$ interesse acerca do pensamento de Zenão faz com que muitos comentadores do Parmênides analisem o paradoxo zenoniano presente no diálogo em comparação ao que sabemos dos argumentos do Zenão histórico. Esta atitude pode ser vista, por exemplo, em Próclus, que interpreta o paradoxo presente no Parmênides em função do conteúdo de uma obra atribuída a Zenão, na qual este paradoxo estaria descrito (In Parm. $694)^{6}$.

Nos comentadores modernos, esta abordagem também parece prevalecer. Assim, Cornford dedica toda primeira seção de seu comentário ao Parmênides à questão da relação entre Zenão e seus oponentes da escola pitagórica7 ${ }^{7}$. Brisson, igualmente, passa boa parte de sua introdução ao Parmênides discutindo a relação entre as teses de Zenão e Parmênides, não como personagens do drama platônico, mas como figuras históricas ${ }^{8}$. Ambos autores, mesmo reconhecendo a escassez de fontes sobre o tema, acabam por projetar a sua compreensão do pensamento do Zenão histórico na interpretação do papel desta figura no interior de nosso diálogo.

Em contrapartida a essa atitude, a importância do paradoxo de Zenão na estrutura dramática e argumentativa do Parmênides tem sido, na maior parte das vezes, negligenciada pelos comentadores. Como observa Harte, "muito constantemente, o interesse em examinar a relação entre as deduções [da segunda parte do diálogo] e a crítica de Parmênides às Formas deu-se às custas de uma consideração da conversa inicial entre Sócrates e Zenão"9. Uma das razões para esta negligência está, sem dúvida, no fato de que os comentadores consideram relativamente clara a relação desta conversa inicial com o restante da obra. Segundo a opinião geral, o paradoxo de Zenão serve como um pretexto para que Sócrates apresente a Teoria das Ideias. Sendo assim, os comentadores tecem rápidas considerações sobre o paradoxo de Zenão e, na maior parte das vezes, já em função da solução apresentada por Sócrates para este paradoxo ${ }^{10}$.

No entanto, caso adotemos este tipo de interpretação para o papel do paradoxo de Zenão no diálogo, estaremos, de início, comprometendo a unidade da argumentação do Parmênides. Pois, segundo este ponto de vista, o paradoxo de Zenão não está diretamente implicado na argumentação do restante do diálogo e não passa de uma deixa dramática para entrada em cena de Sócrates e sua teoria. Sendo assim, evitarei abrir a caixa de pandora do conteúdo do pensamento eleático e me limitarei a oferecer uma interpretação para o paradoxo de Zenão à altura do papel de destaque que este argumento recebe no nosso diálogo. No Parmênides, o paradoxo de Zenão dá ensejo a toda discussão subsequente. Portanto, segundo o princípio de relação entre os argumentos do diálogo esboçado na seção precedente, os conceitos envolvidos neste paradoxo devem ressoar por todo o restante da argumentação.

\footnotetext{
${ }^{6}$ Dillon, em sua introdução ao Comentário ao Parmênides de Proclo, defende a tese de que Proclo dá claros sinais de possuir um manuscrito da obra de Zenão e que, portanto, devemos considerar válidas suas observações sobre o conteúdo desta obra. A mais famosa destas observações afirma que o paradoxo apresentado no Parmênides fazia parte de um livro que conteria quarenta argumentos. (cf. MORROW\&DILLON, Proclus' Commentary on Plato's Parmenides, p. xxviii-xliii).

${ }^{7}$ CORNFORD, Plato and Parmenides, p. 53-62.

${ }^{8}$ BRISSON, Platon Parmenide, p.15-28.

${ }^{9}$ HARTE, Plato on Parts and Holes, p.52.

${ }^{10}$ Allen, Plato's “Parmenides”, é uma exceção.
} 


\section{Dois sentidos de multiplicidade e unidade implicados na argumentação zenoniana}

A narrativa de Céfalo inicia-se com a descrição de uma leitura pública dos "escritos de

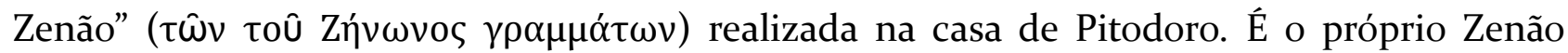
quem realiza a leitura e Sócrates, acompanhado de muitos outros, faz parte da audiência que se reuniu ansiosa para escutar o que seria dito, uma vez que esta era a primeira vez que tais escritos eram trazidos para Atenas. Ao final da apresentação, Sócrates pede para que seja lida, novamente, a primeira hipótese do primeiro argumento e, ao fim, diz:

Que queres dizer com isso, Zenão? Que, se os seres são múltiplos, então é preciso que eles sejam tanto semelhantes quanto dessemelhantes, mas que isso é impossível, pois nem as coisas dessemelhantes podem ser semelhantes nem as semelhantes, dessemelhantes? Não é isso que queres dizer?

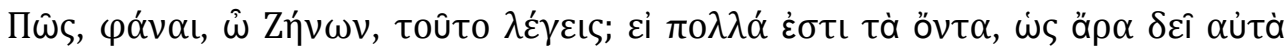

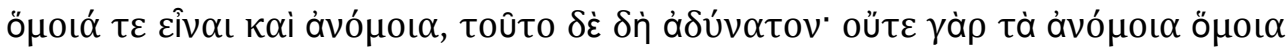

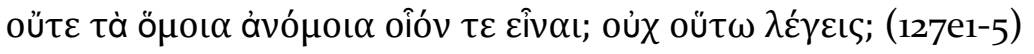

Zenão responde afirmativamente e somos apresentados, assim, ao primeiro argumento do diálogo. Platão constrói este argumento de maneira bastante resumida, nos fornecendo, apenas, as premissas e a conclusão da argumentação zenoniana. Fica claro, a partir do resumo de Sócrates, que estamos lidando com uma redução ao absurdo da tese pluralista, segundo a

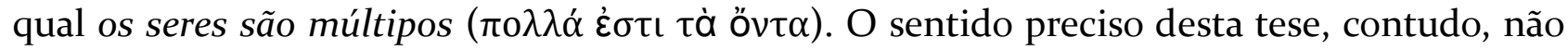
está claro de imediato. Sobretudo, porque, logo depois, Sócrates irá reformulá-la por meio do

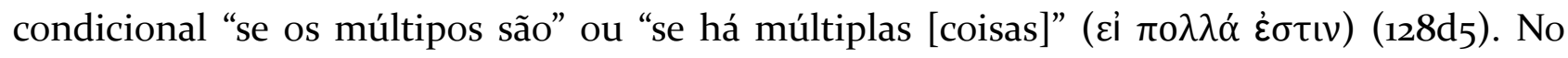

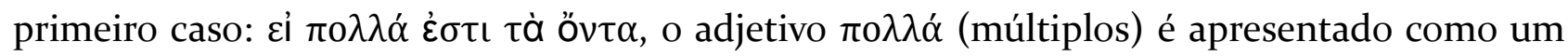

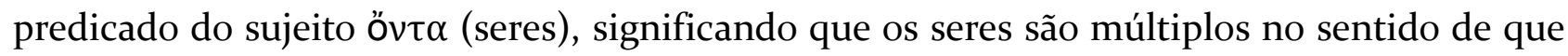

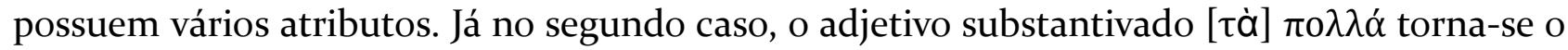
sujeito de uma sentença absoluta, podendo ser traduzida por "se múltiplas [coisas] são" ou "se há múltiplas [coisas]"11.

Temos, portanto, dois sentidos distintos para o argumento de Zenão. O argumento pode estar visando demonstrar a impossibilidade de uma pluralidade numérica, isto é: da tese de que há mais de uma coisa no mundo, ou pode estar visando demonstrar a impossibilidade de uma mesma coisa possuir mais de um atributo. Neste último caso, seu objetivo é demonstrar que cada coisa é perfeitamente simples, homogênea e indivisível. Naturalmente, estas duas teses são independentes uma da outra. Afinal, podemos sustentar que só há uma coisa no mundo, porém considerando esta coisa como múltipla, dotada de várias partes ou atributos. Ao passo que, por outro lado, podemos sustentar que há várias coisas, no entanto considerarmos cada uma delas como simples e indivisível. Sócrates, contudo, oferece tanto $\varepsilon$

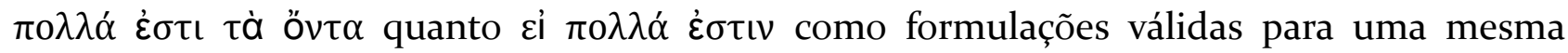
hipótese. Sendo assim, devemos entender que, ao menos em nosso diálogo, estas duas teses estão sendo apresentadas em conjunto, representando dois lados de uma mesma moeda ou

\footnotetext{
${ }^{11}$ A diferença entre estas duas formulações não é tão bem definida em grego quanto sugerem as traduções por mim apresentadas. Afinal, $\tau \grave{\alpha}$ ỏv $\tau \alpha$ pode estar subentendido como sujeito da segunda sentença, o que tornaria as duas formulação idênticas. Trata-se de um caso de ambiguidade sintática, em que as duas leituras são possíveis para cada uma das formulações. De acordo com minha interpretação, este tipo de ambiguidade, recorrente na primeira parte do diálogo, é proposital.
} 
duas perspectivas complementares de uma mesma posição filosófica.

Os personagens do Parmênides parecem reconhecer esta dualidade inerente à argumentação zenoniana. Sócrates, por exemplo, dá sinais de sua compreensão deste fato ao ressaltar ora um, ora outro aspecto da argumentação zenoniana. Em 127e8-128a1, por exemplo, Sócrates pergunta a Zenão:

Será que é isso que querem dizer teus argumentos: não outra coisa senão sustentar decididamente, contra tudo o que se afirma, que não há múltiplas

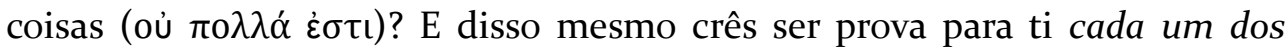
argumentos, de sorte que também acreditas apresentar tantas provas de que não há múltiplas coisas quantos argumentos escrevestes?

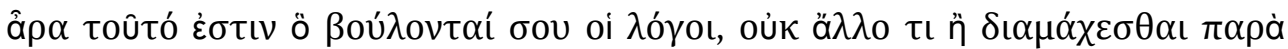

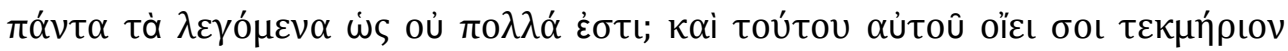

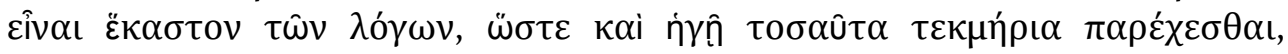

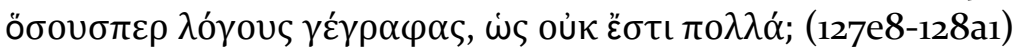

Nesta passagem, por meio do uso repetitivo de expressões no plural, Sócrates indica a

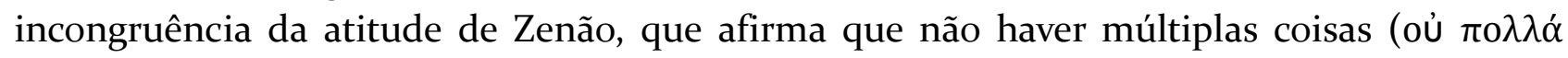
$\dot{\varepsilon} \sigma \tau \iota)$, não obstante fazendo uso de múltiplos argumentos para provar esta afirmação. Como observa Sócrates, ao tentar provar a inexistência de uma pluralidade de coisas por meio de múltiplos argumentos, Zenão enquadra-se em um caso clássico de paradoxo performativo, dando prova justamente daquilo que ele nega ser possível.

Ora, fica claro que, neste momento, Sócrates está tratando o argumento de Zenão como uma prova da impossibilidade da existência de múltiplos indivíduos ou como uma defesa da tese de que só há uma única coisa (monismo numérico). Esta identificação é ainda reafirmada por Sócrates quando ele estabelece, logo em seguida, a equivalência entre o

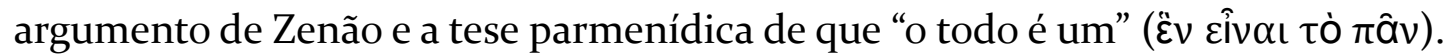

Este comentário é geralmente considerado como a palavra final de Sócrates acerca do sentido da argumentação zenoniana, sendo seguido por uma longa fala em que a Teoria das Ideias é apresentada e o paradoxo de Zenão é superado e não mais invocado na discussão. Esta leitura do texto leva a maior parte dos comentadores a interpretar o paradoxo de Zenão como uma defesa, apenas, da tese do monismo numérico, sem que esteja implicada no paradoxo uma prova da impossibilidade das coisas possuírem múltiplos atributos ${ }^{12}$. O defensor mais radical deste tipo de interpretação é, sem dúvida, Luc Brisson (1990), que, com base nesta passagem, pretende não apenas limitar a argumentação de Zenão a uma afirmação do monismo numérico como, também, identificar a expressão tò $\pi$ âv, traduzida por ele como "o universo" ou "o conjunto de todos os conjuntos de todas as coisas sensíveis", como o sujeito implícito de todas as formulações da tese unitarista ${ }^{13}$.

\footnotetext{
${ }^{12}$ Vide, por exemplo, o comentário de Rossvaer: "Zenão toma como ponto de partida a hipótese de que as coisas são múltiplas. Mas não é exatamente isso o que ele quer dizer. O que ele quer dizer é que o Ser (o todo) é Um, tal como seu mestre. (ROSSVAER, Laborious Games, p. 15). No mesmo sentido, cf. COXON, The Philosophy of Forms, p. 97. O único autor que reconhece a dualidade implicada na argumentação de Zenão é El Murr (Les Forms sans L'ame. Parm. 131a-133a), embora a interpretação oferecida por MacCabe (Unity in Plato's Parmenides) também pressuponha este reconhecimento.

${ }^{13}$ Brisson vai além e identifica tò $\pi \tilde{\alpha} \nu$ como o sujeito subentendido de todas as hipóteses da segunda parte do Parmênides (Platon Parmenide, pp. 18-27). No entanto, ao afirmar a expressão tò $\pi \tilde{\alpha} v$ como o sujeito oculto de todas as expressões em que o um aparece ligado ao verbo "ser", tanto na primeira quanto na segunda parte do diálogo, Brisson está oferecendo uma interpretação, claramente, violenta ao texto do Parmênides. Afinal, Platão
} 
Entretanto, a identificação da argumentação de Zenão com o monismo numérico de Parmênides só é estabelecida, explicitamente, nessa passagem. Por todo o restante do diálogo, Platão faz uso de expressões deliberadamente ambíguas para se referir tanto à tese pluralista, alvo do paradoxo de Zenão, quanto à tese monista defendida por Zenão e Parmênides. Isto fica claro a partir do inventário realizado por Giovanni Casertano, que nos lista todas as formulações das teses monista e pluralista presentes no Parmênides, divididas entre afirmações diretas e formulações hipotéticas ${ }^{14}$. Como afirmações hipotéticas, em sentenças condicionais, temos:

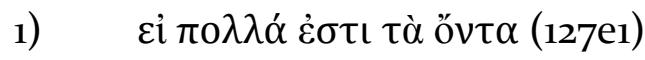

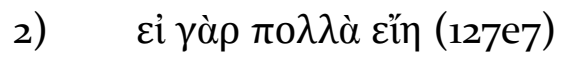

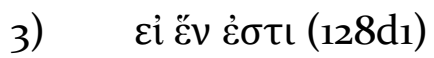

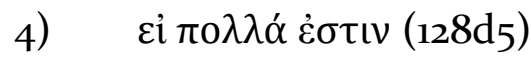

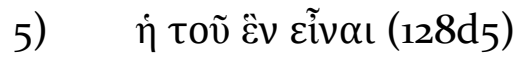

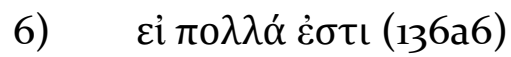

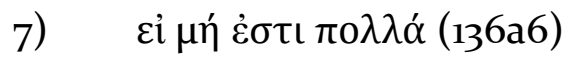

Como assertivas diretas, temos:

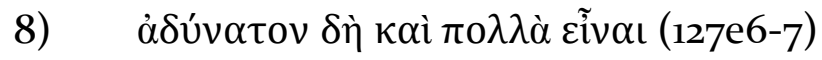

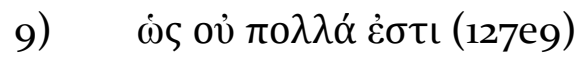

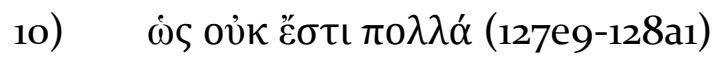

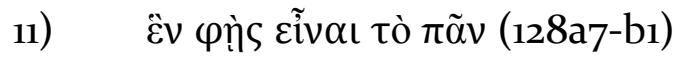

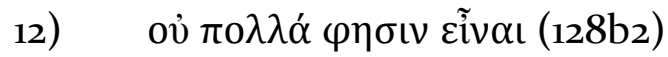

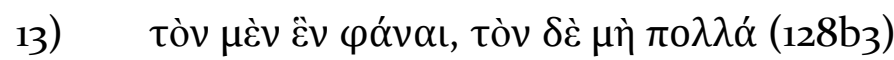

14) $\tau \grave{\alpha} \pi \mathrm{o} \lambda \lambda \grave{\alpha} \lambda \bar{\varepsilon}^{\prime} \gamma \mathrm{ov \tau \alpha \varsigma}$

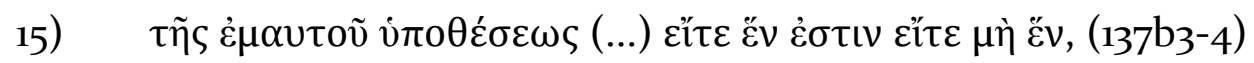

Com base neste inventário, é possível constatar que somente na passagem número 11

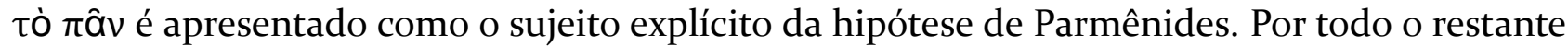
do diálogo, Platão faz uso de expressões ambíguas, sem sujeito definido, para se referir tanto às teses de Parmênides e Zenão quanto às teses dos defensores do pluralismo ${ }^{15}$. Portanto, dado o grande número de passagens em que a tese monista de Zenão e Parmênides não aparece diretamente vinculada ao monismo numérico, não temos razão para projetar aquilo que encontramos em uma única passagem como a interpretação definitiva para todas as outras.

Caso tenhamos em mente a ambiguidade inerente à formulação do paradoxo de Zenão, poderemos notar que o segundo sentido de multiplicidade implicado na sua argumentação emerge como a interpretação natural para outras passagens do diálogo. Em uma destas passagens, a possibilidade de um mesmo indivíduo possuir uma multiplicidade de partes é apresentada por Sócrates como um dos resultados da sua solução para o paradoxo. Em 129c, Sócrates diz:

dificilmente esconderia a chave para compreensão de todo o diálogo em uma única ocorrência da expressão tò $\pi \tilde{\alpha} v$, em meio a esta fala, aparentemente, despretenciosa de Sócrates.

${ }^{14}$ Cf. CASSERTANO, Critica delle idee ed argomentazione dialettica nella prima parte del "Parmenide", pp. 386388 .

${ }^{15}$ Com a exceção, é claro, da sentença número 1, que, como já observamos, apresenta $\pi 0 \lambda \lambda \alpha$ como predicativo

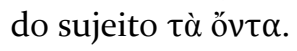


Mas se alguém demonstrar que eu sou $u m^{16}$ e múltiplas coisas, que há nisso de espantoso? Quando quiser mostrar que eu sou múltiplas coisas, dirá que uma coisa é meu lado direito, outra, o esquerdo, e que uma coisa é a frente, outra, a parte de trás, e do mesmo modo com relação à parte inferior e posterior, pois participo, creio, da quantidade; e, por outro lado, quando [quiser mostra] que sou um, dirá que, dos sete que aqui estão, eu sou um homem, participante que sou também do um.

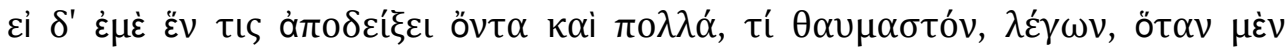

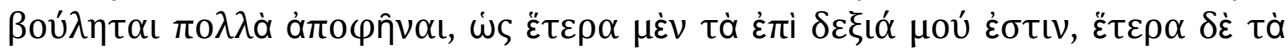

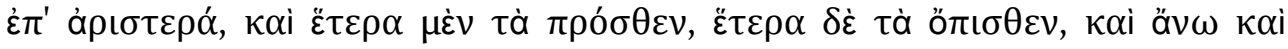

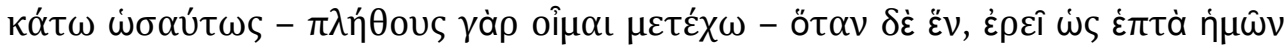

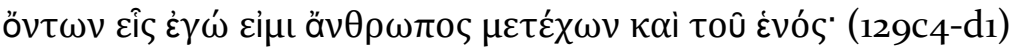

A importância desta fala de Sócrates na compreensão do conteúdo da argumentação de Zenão não parece ter sido notada pelos comentadores. Isto deve-se ao fato desta colocação fazer parte de um discurso mais amplo, no qual Sócrates desafia seus interlocutores a demonstrarem que suas Formas estão sujeitas à predicação de opostos, tal como estão sujeitos, os objetos sensíveis. Contudo, se limitarmos nossa interpretação destas palavras de Sócrates à questão da copresença de opostos, a introdução do tema da unidade e multiplicidade torna-se completamente incidental. Afinal, Sócrates poderia ter apresentado seu desafio por meio de qualquer outro par de propriedades opostas. Na verdade, de acordo com esta linha de raciocínio, o aparecimento dos conceitos de unidade e multiplicidade nessa passagem é, inclusive, desnecessário, uma vez que Sócrates já havia formulado seu desafio por meio das propriedades "semelhante" e "dessemelhante". No entanto, não podemos considerar meramente ocasional esta específica formulação, sobretudo em meio a uma discussão centrada na questão da viabilidade teórica da noção de multiplicidade. É claro que, na dinâmica conversacional do diálogo, qualquer afirmação sobre o tema da unidade/multiplicidade remete o leitor diretamente ao paradoxo de Zenão e à compreensão de seu significado.

A observação de Sócrates deixa de ser irrelevante e passa a fazer sentido, se entendermos o paradoxo de Zenão como uma prova, também, da impossibilidade de uma coisa única qualquer possuir múltiplos atributos. Sócrates está tornando explícito, nesta passagem, o segundo sentido de multiplicidade negado pela argumentação de Zenão, a multiplicidade de partes ou atributos de um mesmo indivíduo. Segundo Sócrates, não há nada de espantoso, ao contrário do que pretende afirmar Zenão, no fato de uma dada coisa única ser, também, múltipla, dotada de várias partes.

Portanto, para defender o monismo de seu mestre Parmênides, Zenão pretende demonstrar a contradição envolvida na admissão da multiplicidade tout court, quer esta seja entendida como uma multiplicidade de indivíduos, quer como uma multiplicidade de atributos de um mesmo indivíduo. Como veremos, o reconhecimento desta dualidade da argumentação zenoniana se mostrará essencial para a compreensão dos argumentos seguintes. Pois estes dois sentidos de multiplicidade estarão implicados na solução de Sócrates para o paradoxos de Zenão, assim como farão parte da estratégia utilizada por Parmênides na sua contra-argumentação à solução socrática.

\footnotetext{
${ }^{16}$ Coloco "um" em itálico, nesta e nas seguintes passagens, para diferenciar o atributo "ser-um" do artigo indefinido.
} 


\section{A redução da tese pluralista ao absurdo}

Tendo estabelecido os dois sentidos de multiplicidade afirmados pela tese pluralista e negados pelo monismo de Zenão e Parmênides, podemos passar para a análise do argumento zenoniano. De acordo com o resumo apresentado por Sócrates em 127e1-5, a redução ao absurdo da tese pluralista é operada por Zenão por meio do seguinte raciocínio:

1) Suponha que os seres são múltiplos (tese provisoriamente assumida).

2) Se eles são múltiplos, então eles são tanto semelhantes quanto dessemelhantes.

3) Logo, os seres são tanto semelhantes quanto dessemelhantes (a partir de 1 \& 2)

4) Ora, é impossível que uma mesma coisa seja semelhante e dessemelhante.

5) Portanto, os seres não são múltiplos. (afirma-se a negação de 1 com base na contradição entre $3 \& 4)^{17}$.

A invenção do método de redução ao absurdo, que consiste em assumir temporariamente uma tese para, a partir dela, derivar uma contradição e, assim, concluir a negação da tese inicial, não deve ser atribuída a Zenão, embora saibamos que ele tenha usado extensivamente este método argumentativo. Segundo Thomas Heath, o método de redução ao absurdo pode ter sua origem traçada até a escola pitagórica e, no tempo de Platão, este argumento já era usado largamente em provas matemáticas envolvendo teoria dos números ${ }^{18}$. Sendo assim, podemos considerar que os leitores de Platão não viam com estranheza este tipo de argumentação.

Da mesma maneira, a premissa número 2 do argumento de Zenão parece bastante plausível e dificilmente teria sua validade objetada. Zenão pode estar argumentando, por exemplo, que os múltiplos seres, como seres, são semelhantes entre si, enquanto que como múltiplos e, portanto numericamente distintos uns dos outros, são dessemelhantes; ou, ainda, que as diversas partes de um indivíduo são semelhantes entre si, enquanto partes de um mesmo indivíduo, porém dessemelhantes, enquanto partes distintas.

No entanto, chama muita atenção o conteúdo da premissa número 4 do argumento. Segundo esta premissa, uma mesma coisa não pode ser, ao mesmo tempo, semelhante e dessemelhante. Mas por quê? Podemos pensar em miríades de casos em que uma mesma coisa é tanto semelhante quanto dessemelhante. Sócrates e Platão, por exemplo, são semelhantes, pelo fato de ambos serem atenienses, no entanto são dessemelhantes em vários outros aspectos, como em idade, condição social, etc. Enquanto intérpretes, devemos tentar entender porque os interlocutores do Parmênides consideram intrigante e paradoxal o fato de uma dada coisa possuir, simultaneamente, propriedades opostas, mesmo quando estas propriedades representam termos relativos (semelhante-dessemelhante, maior-menor, etc.).

A interpretação mais comumente aceita para o paradoxo consiste em dizer que Zenão estaria tratando predicados relacionais como predicados monádicos (ou adjetivos). Assim, ele estaria ignorando o complemento existente nos predicados relacionais e tratando a propriedade "ser semelhante $a x$ " como equivalente à propriedade "ser semelhante simpliciter", isto é: estaria tratando um predicado incompleto (que necessita de um complemento para ser significativo) como um predicado completo (significativo por si só).

\footnotetext{
${ }^{17}$ Trata-se de um argumento em Modus Tollendo Tollens, isto é, um argumento que, negando (tollendo) o consequente da implicação expressa na premissa, nega (tollens), por consequência lógica, também o antecedente. Em notação formal: $\mathrm{P} \rightarrow \mathrm{Q} ; \quad \sim \mathrm{Q} ; \quad \quad \quad \sim \mathrm{P}$

${ }^{18}$ Cf. HEATH, A History of Greek Mathematics, pp. 294-295.
} 
Negligenciada a diferença entre estes dois tipos de predicados, uma sentença do tipo: "A é maior que $B$ e menor que C." passa a ser equivalente a "A é maior e menor simpliciter.", tornando-se tão contraditória quanto a sentença "A é quadrado e redondo."

Este tipo de interpretação foi primeiramente apresentada por Cornford, segundo o qual: "nenhuma distinção é traçada entre qualidades e relações. Grandeza é tratada como se fosse uma qualidade como Brancura, inerente à pessoa grande" ${ }^{\prime 19}$. Cornford observa, ainda, que este tipo de raciocínio parece ser particularmente favorecido pela sintaxe grega, que permite sentenças do tipo: "Simmias é grande em relação ( $\pi \rho$ òs) a Sócrates" ou, ainda, "Simmias tem grandeza com relação ( $\pi \rho$ òs) a Sócrates", nas quais o segundo termo da relação binária "ser-maior-que" não é necessariamente introduzido por um pronome relativo, mas pode ser introduzido pela preposição $\pi \rho$ òs. Este fato sintático teria, supostamente, induzido os pensadores gregos a negligenciar o caráter relacional de propriedades como "sersemelhante-a" ou "ser-maior-que", levando-os a classificá-las como propriedades monádicas do tipo "ser-branco" ou "ser-belo".

No entanto, esta análise linguística, por si só, não pode ser considerada uma explicação satisfatória. Caso assim fosse, Sócrates poderia simplesmente argumentar em termos estritamente gramaticais e afirmar que usamos sentenças significativas com predicados relativos cotidianamente e que, portanto, o paradoxo de Zenão deveria ser simplesmente desconsiderado. Pois, só há contradição quando propriedades opostas são atribuídas a uma mesma coisa, ao mesmo tempo, da mesma maneira e em relação a uma mesma coisa ${ }^{20}$.

A ausência de distinção entre predicados relacionais e predicados completos no argumento de Zenão, no entanto, nos remete diretamente a um tema extremamente recorrente nos diálogos: a copresença de propriedades opostas. Como sabemos, em diversos diálogos, Sócrates e seus interlocutores consideram a copresença de propriedades opostas nos objetos sensíveis algo intrigante e merecedor de uma explicação teórica complexa (vide: Phd. 74a-c; Symp. 210-211b, Rep. 523-525). Na realidade, o fato das entidades sensíveis estarem submetidas a este tipo de predicação constitui aquilo que mais propriamente as caracteriza, o que fica claro pelo uso de predicados relacionais nas demonstrações socráticas da diferença entre o modo de ser das Formas e o modo de ser das coisas do mundo sensível. Submetidas a uma multiplicidade de relações, as entidades sensíveis estão sempre sujeitas à predicação de opostos, o que é tido por Sócrates como uma evidência cabal da contradição interna e deficiência ontológica desses objetos.

Portanto, devemos entender que os predicados "semelhante" e "dessemelhantes" do argumento de Zenão estão sendo empregados para ilustrar o fato de que os objetos sensíveis têm suas propriedades definidas pelas relações em que estão inseridos, o que resulta na copresença de opostos em um mesmo objeto e lhes confere um caráter contraditório. Ora, é evidente que a extinção das mútuas relações existentes entre os objetos sensíveis seria suficiente para eliminar o problema da copresença de opostos, pois um único objeto privado de qualquer relação é somente idêntico a si mesmo.

É justamente esta a estratégia da argumentação zenoniana. Reduzindo a multiplicidade dos objetos sensíveis a uma única entidade, Zenão elimina por completo as múltiplas relações entre eles, consequentemente resolvendo o problema da copresença de opostos. Assim, enquanto Sócrates usa a copresença de opostos para caracterizar a deficiência do mundo sensível e, ainda, postular a existência de entidades não submetidas às relações que

\footnotetext{
${ }^{19}$ CORNFORD, Plato and Parmenides, p.78.

${ }^{20}$ De fato, em uma passagem da República IV (436b-c), Sócrates formula uma versão da Lei da NãoContradição, na qual todas estas qualificações são mencionadas.
} 
geram esta copresença, Zenão usa esta característica para negar toda possibilidade de multiplicidade, extinguindo por completo qualquer tipo de relação e postulando a existência de uma única coisa privada de qualquer atributo salvo sua auto-identidade.

\section{A solução de Sócrates para o paradoxo de Zenão}

A despeito de todas as polêmicas acerca da interpretação do Parmênides, a compreensão da solução oferecida por Sócrates ao paradoxo de Zenão destaca-se como um ponto de notável consenso. Os comentadores parecem concordar que a estratégia adotada por Sócrates consiste em desafiar o conteúdo da premissa número 4 do argumento de Zenão, por meio da distinção entre dois tipo de entidades, Formas e objetos sensíveis. Sócrates entende

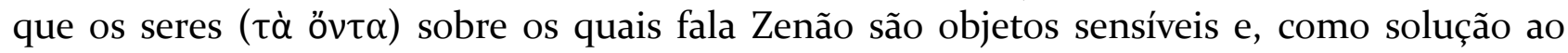
paradoxo, apresenta as Formas como um tipo de entidade imune à copresença de opostos apontada por Zenão.

Recentemente, contudo, até mesmo este aparente consenso foi ameaçado. Sandra Peterson, em seu capítulo sobre o Parmênides para The Oxford Handbook of Plato (2008), distingue sua própria interpretação das interpretações que atribuem a Sócrates uma apresentação técnica da Teoria das Ideias. Ela acredita que "se consideramos que Sócrates ostenta uma nova teoria de caráter técnico, com entidades desconhecidas [isto é: as Formas] (...) não percebemos o genuíno poder de sua simples refutação" ${ }^{\text {.1 }}$.

No entanto, como se daria a solução do paradoxo, caso Sócrates não apelasse para Formas inteligíveis? Segundo a interpretação proposta por Peterson, "Sócrates simplesmente aponta pressuposições inegáveis da fala cotidiana (undeniable presuppositions of customary speech)" para refutar Zenão ${ }^{22}$. De acordo com Peterson, a estratégia geral da argumentação de Sócrates consiste em demonstrar que predicados opostos são ordinariamente atribuídos às coisas. Sendo assim, seu objetivo não seria provar a invalidade do argumento de Zenão, mas sim a sua irrelevância: ao fim de sua argumentação, Sócrates teria demonstrado que o argumento de Zenão não apresenta um paradoxo, mas apenas uma verdade amplamente reconhecida.

Contudo, é preciso observar que a interpretação proposta por Peterson encontra-se em clara oposição ao que um leitor dos diálogos poderia esperar. Segundo o argumento de Zenão, é impossível que os seres sejam tanto semelhantes quanto dessemelhantes ou, de maneira geral, que uma dada coisa possua qualquer par de predicados opostos (F e não-F). Ora, um leitor acostumado com o tipo de argumentação que Sócrates desempenha nos diálogos da fase média espera, naturalmente, que as Formas sejam apresentadas como solução para este problema.

Esta expectativa é plenamente satisfeita quando Sócrates pede a Zenão que aceite a existência de "uma Forma em si e por si da Semelhança e, por outro lado, uma outra Forma,

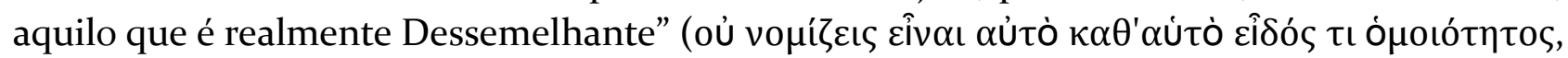

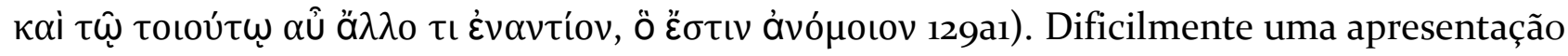
das Formas poderia ser feita de maneira mais explícita. Além do termo عîßos, Sócrates usa as

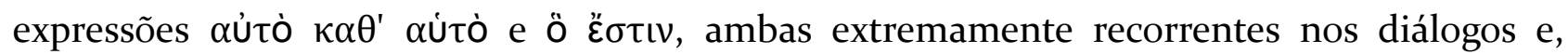
indubitavelmente, parte do vocabulário relativo às Formas. Fica claro, portanto, que Sócrates

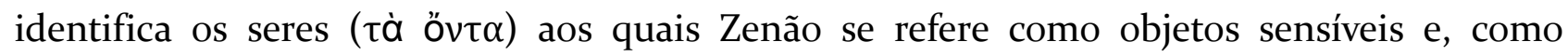

\footnotetext{
${ }^{21}$ PETERSON, "Parmenides", pp. 383-411.

${ }^{22}$ PETERSON, "Parmenides", p. 387.
} 
primeiro passo na solução do paradoxo, introduz suas Formas na discussão.

No entanto, a simples apresentação de entidades imunes à copresença de opostos não se configura como uma solução ao paradoxo. A premissa 4 de Zenão afirma a impossibilidade das coisas serem, simultaneamente, semelhantes e dessemelhantes, o que certamente não exclui a possibilidade de algo ser, exclusivamente, semelhante ou dessemelhantes. Para que a premissa 4 seja falsificada, é preciso que Sócrates demonstre como os seres podem possuir propriedades opostas, sem que isso implique em uma contradição. Portanto, de modo a servirem de solução ao paradoxo, as Formas precisam não apenas estar imunes à copresença de opostos, mas sobretudo explicar esta copresença nos objetos sensíveis. Para que isto seja feito, Sócrates introduz a noção de participação (aqui representada pelos verbos

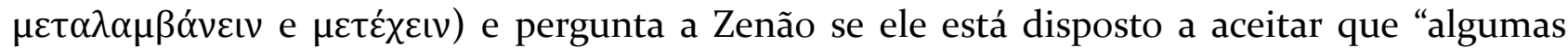
coisas, tendo participação na Semelhança, se tornam semelhantes, (...) que outras, tendo participação na Dessemelhança, [se tornam] dessemelhantes, e que outras, [tendo participação] em ambas, se tornam semelhantes e dessemelhantes" (129a3-8).

Caso Zenão esteja disposto a aceitar estas duas hipóteses: 1) que existem Formas e 2) que os objetos sensíveis participam destas Formas, a aparente contradição presente na premissa 4 do seu argumento pode ser dissolvida. Pois, uma vez que estes dois pontos lhe sejam concedidos, Sócrates estará apto a demonstrar como a copresença de propriedades opostas nos objetos sensívieis pode ser explicada por meio da relação de participação que estes objetos mantêm com as Formas ${ }^{23}$.

No Parmênides, Sócrates não desenvolve em pormenores esta explicação, se limitando a dizer que mesmo que todas as coisas sensíveis tenham participação em ambas estas Formas e, em consequência desta participação, sejam semelhantes e dessemelhantes, nada há nisso de espantoso (129a8-b1). Esta brevidade da explicação de Sócrates pode ser remediada se relacionarmos a solução aqui apresentada para o paradoxo de Zenão com a explicação oferecida, no Fédon (101-103), para o fato de Simmias ser grande em relação a Sócrates e pequeno em relação a Fédon. A assimilação entre as duas explicações parece justificada, uma vez que, em ambos os diálogos, vemos Sócrates oferecer a Teoria das Ideias como solução para o mesmo problema: a copresença de propriedades (relacionais) opostas nos objetos sensíveis $^{24}$.

Adotando o paralelismo entre estas duas explicações, podemos entender que, tal como acontece no Fédon, a semelhança e dessemelhança, no Parmênides, deixam de ser predicados atribuídos diretamente ao sujeito em questão e passam a ser predicados das propriedades

\footnotetext{
${ }^{23}$ Note que Sócrates apresenta estas duas hipóteses (a existência das Formas e a relação de participação) por meio de uma pergunta (129a1-3). Isto indica que ele está introduzindo um novo material conceitual e que espera um assentimento, por parte de seus interlocutores, com relação à viabilidade teórica destas hipóteses. A estratégia de Parmênides será admitir, temporariamente, a validade das hipóteses de Sócrates, com o objetivo de submetê-las a uma nova redução ao absurdo.

${ }^{24}$ Além da identidade de temas, as passagens do Fédon e do Parmênides apresentam grande semelhança de

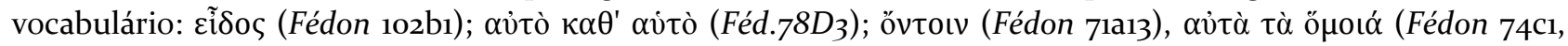

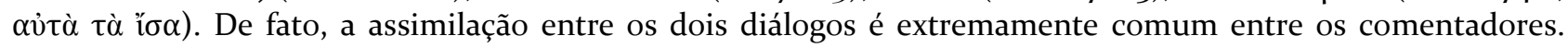
Scolnicov, por exemplo, afirma que "esta passagem é uma breve reafirmação da doutrina das Formas desenvolvida no Fédon" (SCOLNICOV, Plato's Parmenides, p. 48). Gill oferece sua explicação para resolução do paradoxo de Zenão por meio da teoria apresentada no Fédon (cf. GILL, Plato: Parmenides, p. 12-18). Cornford também adota a estratégia de explicar a solução do paradoxo através da analogia com a solução do problema da copresença de opostos no Fédon e afirma haver, já em 1951, aceitação geral (it is generally agreed) de que "a teoria das ideias aqui apresentada é idêntica à afirmada anteriormente no Fédon." (CORNFORD, Plato and Parmenides, p. 70). Ainda, Brisson (Platon Parmenide:introduction et notes, p. 29), Sayre (Parmenides' Lesson, p. 65) e Turnbull (The Parmenides and Plato's Late Ontology, p. 16) assumem a identidade entre a teoria do Fédon e a teoria do Parmênides.
} 
imanentes $^{25}$ que este sujeito possui devido à relação de participação que mantém com as Formas.

No Fédon, propriedades imanentes são evocadas como parte do argumento que procura provar a diferença ontológica entre Formas e objetos sensíveis (74b7-c5) e, em seguida, fazem parte da explicação da copresença das propriedades opostas (Grande e Pequeno) em Simmias (101-103). Em ambas as passagens, as propriedades imanentes se diferenciam dos objetos sensíveis que as possuem por não estarem, elas mesmas, sujeitas à predicação de opostos que caracteriza estes objetos. $\mathrm{O}$ paralelismo entre estas passagens do Fédon e nossa passagem do Parmênides torna-se evidente quando consideramos que aủ

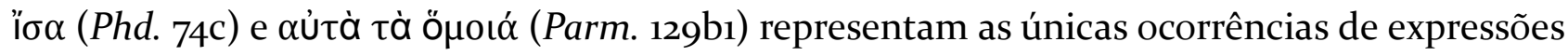
da forma $\alpha$ Ủंà + adjetivo neutro plural, no corpus platônico.

Portanto, encontramos total uniformidade no emprego desse tipo de expressão em Platão. As duas únicas ocorrências desse tipo de expressão são usadas para designar as propriedades imanentes dos objetos sensíveis, adquiridas por meio da relação de participação que estes objetos mantêm com as Formas. Tal como as Formas, as propriedades imanentes não estão sujeitas à copresença de opostos. Porém, em oposição à unidade característica das Formas, estas entidades são múltiplas e possuem um tipo de existência dependente dos

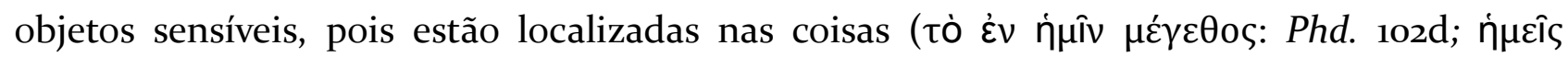

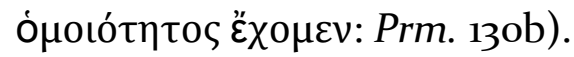

Sendo assim, as múltiplas coisas do paradoxo de Zenão são tanto semelhantes quanto dessemelhantes por participarem, simultaneamente, das Formas do Semelhante e do Dessemelhante e, devido a esta participação, possuírem as propriedades imanentes do semelhante e do dessemelhante como partes de si. Portanto, quando dizemos que o objeto x é semelhante e dessemelhante, estamos nos referindo a este fato de maneira inadequada. Pois não é propriamente o indivíduo $x$ que é semelhante e dessemelhante, mas a semelhança-de-x que é semelhante e a dessemelhança-de-x que é dessemelhante. Estabelecida a diferença entre Forma, propriedades imanentes e objetos sensíveis, não há nada de contraditório no fato de uma mesma coisa possuir, simultaneamente, propriedades imanentes opostas. Afinal, predicados opostos nunca estão sendo atribuídos, propriamente, à mesma coisa.

A hipótese das Formas contradiz o conteúdo da premissa 4 do argumento de Zenão ao explicar aquilo que esta premissa afirmava ser impossível: a copresença de propriedades opostas nos objetos sensíveis. Provada a falsidade da premissa número 4 do argumento de Zenão, todo paradoxo é desfeito. Afinal, a redução ao absurdo da assunção inicial de que as coisas são múltiplas depende, diretamente, da existência de contradição entre as premissas 3 e 4 .

\section{O desafio de Sócrates}

A proximidade entre a Teoria das Ideias apresentada no Parmênides e a ontologia socrática dos diálogos da fase média é reafirmada, ainda, no desafio lançado por Sócrates a seus interlocutores. Logo após a apresentação das Formas como solução ao problema da copresença de opostos, Sócrates compele seus interlocutores a demonstrarem, nas Formas, a validade dos mesmos problemas que Zenão acabara de apontar nos objetos sensíveis. A passagem pode ser dividia em quatro partes:

\footnotetext{
${ }^{25}$ Entendo por "propriedade imanente" o efeito, nos objetos sensíveis, resultante da participação nas Formas.
} 
1) 129b1: Sócrates desafia seus interlocutores a demonstrarem que as propriedades

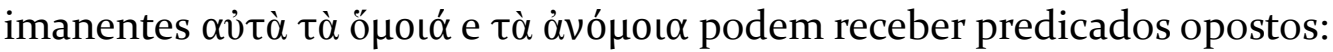

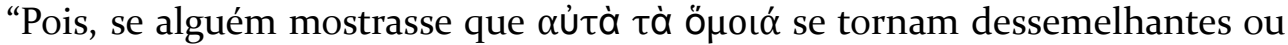
que $\tau \dot{\alpha}$ ờó $\mu$ oı $\alpha$ se tornam semelhantes, seria assombroso, creio".

2) 129b6-c1: Sócrates desafia seus interlocutores a demonstrarem que a Forma da Unidade é múltiplas coisas e o Múltipo é um:

"Mas, se aquilo que é realmente Um, alguém demonstrar que isso mesmo é múltiplas coisas e, de outra parte, que o Múltiplo é um, já disso me espantarei”.

3) 129c1-3: Sócrates desafia seus interlocutores a demonstrarem que as Formas são tanto unas quanto múltiplas:

"E do mesmo modo com respeito a todas as outras coisas: se alguém mostrar que, em si mesmos, os gêneros mesmos e as Formas mesmas são afetados por essas afecções contrárias [unidade e multiplicidade], isso será digno de espanto".

4) 129d6-13oa1: Sócrates desafia seus interlocutores a demonstrarem como as Formas podem estar misturadas e separadas entre si:

Mas, dentre as coisas que há pouco mencionei, se alguém, em primeiro lugar, separasse uma das outras as Formas mesmas em si mesmas - por exemplo: a Semelhança, a Dessemelhança, a Quantidade, o Um, o Repouso, o Movimento e todas as coisas deste tipo - em seguida mostrasse que estas, entre si, podem ser misturadas e separadas, eu pelo menos, disse [Sócrates], ficaria encantado, cheio de espanto, Zenão. Quanto àquelas coisas [sensíveis], acredito terem sido tratadas por ti com muita determinação. Entretanto, eu, como digo, me encantaria muito mais se alguém pudesse, essa mesma aporia, da maneira como expuseste no caso das coisas que se vêem, exibi-la, dessa mesma maneira, também no caso das coisas apreendidas pelo raciocínio, entrelaçadas de todos os modos nas Formas mesmas.

1 e 2 representam, basicamente, o mesmo tipo de desafio. Em 1, Sócrates diz que ficaria

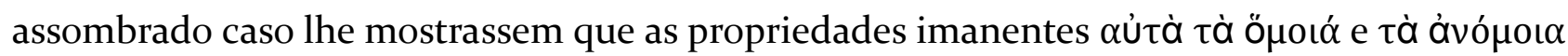
estão sujeitas à predicação de opostos. Em 2, este desafio é expandido para as Formas da Unidade e da Multiplicidade e Sócrates pede que lhe seja demonstrado como o Um é múltiplas coisas e o Múltiplo um. No Fédon (102d-e), Sócrates havia afirmado que o Grande

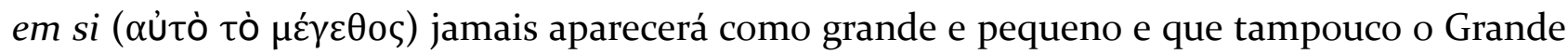

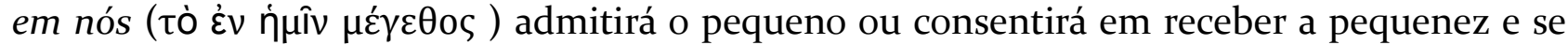
tornar contrário ao que ele é (102e2). A imunidade à predicação de opostos é, portanto, válida

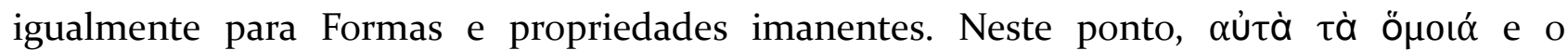

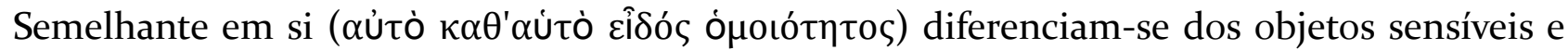
Sócrates desafia seus interlocutores a lhe demonstrarem como qualquer uma destas entidades pode estar sujeita à copresença de opostos que caracteriza os objetos empíricos.

Logo após intimar Zenão e Parmênides a lhe demonstrarem que a Unidade (ő ह̌ $\sigma \tau \iota v$ ह̌v) é múltiplas coisas e que o Múltiplo é um, Sócrates muda o foco de sua argumentação e, deixando de falar de um par específico de Formas, passa a tratar de Formas, em geral ( $\pi \varepsilon \rho i$ $\tau \hat{\omega} \nu$ ä $\lambda \lambda \omega \nu$ ámóv $\nu \omega \nu)$. Sócrates então compele seus interlocutores a lhe provarem 3: que as 
Formas, elas mesmas, são afetadas, simultaneamente, pela unidade e multiplicidade. Os comentadores costumam entender o desafio expresso em 3 como a generalização do problema da copresença de opostos apresentado em 1 e 2. Contudo, como dito anteriormente, não podemos considerar uma mera casualidade o fato de Sócrates escolher as propriedades da unidade e da multiplicidade para operar esta generalização. O debate entre Sócrates e Zenão é motivado pelo tema da unidade/multiplicidade e a reintrodução deste par de conceitos, neste momento, remete o leitor à distinção inicial entre a multiplicidade de objetos sensíveis (as coisas que chamamos muitas: $\tau \hat{\alpha} \lambda \lambda \alpha$ à $\delta \dot{\eta} \pi 0 \lambda \lambda \dot{\alpha} \kappa \alpha \lambda$ oû $\mu \varepsilon v)$ e a unidade característica das

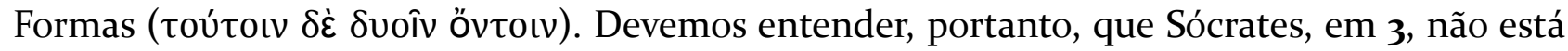
apenas generalizando o problema da copresença de opostos para o conjunto de todas as Formas, mas está apresentando um novo desafio. Sócrates desafia seus interlocutores a lhe provarem que as Formas, entidades caracterizadas por serem únicas e indivisíveis, podem ser caracterizadas pela multiplicidade encontrada nos objetos sensíveis.

Como vimos, o paradoxo de Zenão pressupõe a afirmação da multiplicidade das coisas em dois níveis distintos. Segundo Zenão, os objetos sensíveis são múltiplos tanto numericamente quanto por serem divisíveis em múltiplas partes e receberem múltiplos predicados. Em paralelo a esta dualidade inerente ao conceito de multiplicidade adotado por Zenão, as Formas platônicas são ditas únicas tanto numericamente, por só haver uma Forma da Beleza, em contraste com a pluralidade de objetos belos, quanto por serem incompostas e indivisíveis. Neste momento do desafio, devemos pressupor que os dois sentidos de unidade e multiplicidade estão em jogo e que Sócrates está desafiando seus interlocutores a demonstrarem a multiplicidade das Formas tout court, seja ela entendida como a existência de uma multiplicidade numérica (diversas Formas da Beleza, por exemplo) ou uma multiplicidade de partes ou atributos de uma mesma Forma.

Por fim, em 4, Sócrates afirma que ficaria surpreso caso alguém "separasse uma das outras as Formas e, em seguida, mostrasse que estas Formas, entre si, podem ser misturadas e separadas”. O sentido preciso desta afirmação não está claro de início e seu significado deve ser acessado pela explicação que se segue. Nas sentenças seguintes, Sócrates esclarece que sua surpresa está relacionada à possibilidade de alguém expor, no caso das Formas, a aporia que Zenão acabara de expor com relação às coisas sensíveis. Como vimos, a aporia apresentada por Zenão consiste em afirmar que os objetos sensíveis são múltiplos e, por conta disso, estão sujeitos à predicação de propriedades opostas. Portanto, devemos entender que o entrelaçamento ao qual se refere Sócrates implica na demonstração de que as Formas são, tal como os objetos sensíveis, múltiplas e, por conta desta multiplicidade, estão sujeitas à predicação de opostos.

Em sua fala, Sócrates enumera uma série de pares de Formas opostas: Semelhança/Dessemelhança, Quantidade/Um, Repouso/Movimento. Como observa Allen, o pronome $\tau \alpha \hat{\tau} \tau \alpha$ em $129 e 2$ possui como antecedente estas Formas tomadas como pares e não cada uma delas isoladamente ${ }^{26}$. Sendo assim, a passagem afirma que não podemos considerar cada um destes pares de Formas como separados e, ao mesmo tempo, supor que os dois membros do par estão misturados e caracterizando um ao outro.

Ora, está claro que o entrelaçamento ou participação de uma Forma em outra faria com que elas perdessem sua unidade e uniformidade característica e passassem a possuir uma multiplicidade de partes e atributos ${ }^{27}$. Além disso, caso Formas opostas estejam entrelaçadas

\footnotetext{
26 ALLEN, Plato's “Parmenides”, p. 101.

${ }^{27}$ No argumento desenvolvido em 142c8-143a2, por exemplo, conclui-se que se o um é, então o um é constituído de partes. Pois, afirmar que "o um é” equivale a afirmar que uma parte do um participa da unidade e outra
} 
entre si, cada uma delas terá um predicado contrário à sua auto-predicação (a Semelhança será dessemelhante, o Movimento estará em repouso, etc.). Portanto, em 4, Sócrates recapitula os desafios expressos anteriormente e reafirma a distinção entre Formas e objetos sensíveis expressa em sua solução ao paradoxo de Zenão.

O desafio apresentado por Sócrates retoma, portanto, aspectos fundamentais da Teoria das Ideias: a uniformidade das Formas, que se caracterizam por estarem imunes à predicação de opostos, e a unidade destas entidades, que são numericamente singulares. Estas características estão mutuamente implicadas, pois as Formas são ditas únicas e homogêneas por serem, de maneira exclusiva, auto-predicativas. Em contraste como as coisas sensíveis, sujeitas a uma diversidade de predicados, inclusive predicados opostos, as Formas são, exclusivamente, aquilo que elas são. A Forma $\mathrm{F}$ é apenas $\mathrm{F}$ e nada mais, estando imune à presença da propriedade oposta não-F e, de maneira geral, a qualquer outro tipo de predicação ${ }^{28}$. Estas características das Formas são a base da distinção ontológica entre Formas e objetos sensíveis e se encontram articuladas na solução de Sócrates para o paradoxo de Zenão. Zenão acredita que as coisas são múltiplas e, por causa disso, estão sempre sujeitas à predicação de opostos. Com o objetivo de desfazer o paradoxo, Sócrates apresenta um novo tipo de entidade, caracterizada pela sua unidade e uniformidade. Segundo Sócrates, estas entidades podem desfazer o problema da copresença de opostos por serem a causa das propriedades encontradas nos objetos sensíveis e por estarem, elas mesmas, imunes à multiplicidade e copresença de opostos encontrada nos objetos sensíveis.

Sendo assim, a demonstração de que as Formas são, elas mesmas, sujeitas à copresença de opostos retiraria destas entidades a capacidade de se apresentarem como causas das propriedades dos objetos sensíveis. Pois, segundo a compreensão de causalidade apresentada por Sócrates no Fédon (96-101), é justamente o fato do Grande nunca se apresentar como pequeno o que faz dele o candidato mais adequado para o cargo de causa da grandeza das coisas sensíveis. A Forma da Beleza deve ser incondicionalmente bela para assegurar o seu papel de causa da beleza nas coisas. Por outro lado, a atribuição de multiplicidade às Formas abriria a possibilidade do paradoxo de Zenão se repetir em cada uma destas entidades, quer entendamos esta multiplicidade como uma multiplicidade numérica ou como uma multiplicidade de atributos. Pois, ou bem cada Forma seria composta por partes semelhantes entre si (por serem partes de uma mesma Forma) e, ao mesmo tempo, dessemelhantes (por serem partes distintas), ou bem as múltiplas Formas de F seriam semelhantes (por serem, todas elas, Formas de uma mesma propriedade F) e dessemelhantes (por serem numericamente distintas). Em ambos os casos, as Formas estariam sujeitas aos mesmos problemas, encontrados nos objetos sensíveis, que, supostamente, deveriam solucionar.

O desafio lançado por Sócrates é, portanto, uma consequência direta da sua solução para o paradoxo de Zenão. A validade da hipótese das Formas como solução ao paradoxo depende destas entidades manterem estes dois aspectos fundamentais de sua constituição ontológica: imunidade à copresença de opostos e unidade (numérica e aspectual). Afinal, estas características são a base da diferenciação entre Formas e objetos sensíveis e a distinção entre estes dois tipos de entidade não restaria estabelecida, caso estas características, próprias dos objetos sensíveis, fossem encontradas também nas Formas. Portanto, caso a multiplicidade e predicação de opostos apontadas por Zenão nos objetos sensíveis sejam

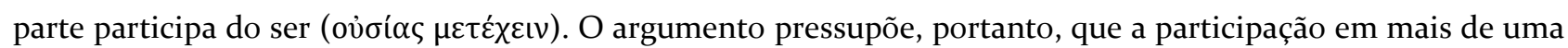
Forma (entrelaçamento) é suficiente para concluir a existência de múltiplas partes do objeto participante.

${ }^{28}$ As afirmações de que $\mathrm{F}$ é única, uniforme, indivisível etc. representam meta-predicados atribuídos a todas as Formas. Estes meta-predicados devem ser entendidos como afirmações restritas ao âmbito da Teoria das Ideias e não entram em conflito com a auto-predicação das Formas. 
válidas para as Formas, a solução apresentada por Sócrates se mostrará falsa e o paradoxo de Zenão permanecerá irresoluto.

A importância do desafio de Sócrates para a compreensão da estrutura do Parmênides dificilmente pode ser superestimada. A fala em que Sócrates soluciona o paradoxo de Zenão e, em seguida, desafia seus interlocutores a provarem a falsidade de sua resolução representa o mais longo discurso ininterrupto do diálogo e possui um forte apelo dramático. No desafio que encerra esta fala, Sócrates usa as palavras "maravilhado", "encantado" e seus cognatos nada menos do que oito vezes e deixa bem claro ao leitor quão arraigado é o seu comprometimento com as teses da uniformidade e unidade das Formas e quão chocante e arrasador seria o reconhecimento da falsidade destes princípios fundamentais de sua teoria. Esta insistência no tema do maravilhamento de Sócrates faz parte da estratégia dramática adotada por Platão, que pretende chamar atenção para importância destas duas características fundamentais da constituição ontológica das Formas e antecipar para o leitor o esquema geral do ataque à Teoria das Ideias que será realizado por Parmênides. Afinal, como sabemos, Parmênides aceitará o desafio lançado por Sócrates e localizará suas críticas, justamente, nos princípios de uniformidade e unidade das Formas. Por meio da sequência de paradoxos que compõem o restante da primeira parte do diálogo, Parmênides irá provar a Sócrates como estas características das Formas mostram-se irreconciliáveis com a noção de participação e, de maneira geral, com a tese de que as Formas são causas das propriedades dos objetos sensíveis.

\section{Referências}

ALLEN, R. E. Plato's Parmenides. Translated with comment. New Haven: Yale University Press, 1997.

BRISSON, L. Platon Parmenide: introduction et notes, Paris: GFlamarion, 1990.

BRISSON, L. Platon Parmenide:introduction et notes; 2 editon, GF, Paris, 2011

CORNFORD, F. Plato and Parmenides. London: Keagan Paul: 1951.

CASSERTANO, G. Critica delle idee ed argomentazione dialettica nella prima parte del Parmenide. In: Atti del Convegno di Filosofia Bocca di Magra, 1990.

COXON, A. H. The Philosophy of Forms: An Analytical and Historical Commentary on Plato's Parmenides. Assen: Van Gorcum: 1999.

EL MURR, D. “Les Forms sans L'ame. Parm. 131a-133a: Est-il une critique de la participation?”, Anticorum Philosophia, 4, 2010, p.137-16o.

FRONTEROTTA, F. METHEXIS. La Teoria Platonica delle Idee e la Partecipazione delle Cose Empiriche. Pisa: Scuola Normale Superiore, 2001.

GILL, M. L. \& RYAN, P. Plato: Parmenides, Indianapolis: Hackett, 1996.

HARTE, V. Plato on Parts and Holes - The Metaphysics of Structure. Oxford: Clarendon Press, 2002.

HEATH, T. A History of Greek Mathematics. Volume I: From Thales to Euclid Volume II: From Aristarchus to Diophantus. Oxford: Clarendon Press, 1960. 
IGLÉSIAS, M. A relação entre Sensível e Inteligível: methexis ou mímesis. In: PERINE, M. (ed.) Estudos platônicos: sobre o ser e o aparecer; o belo e o bem. São Paulo: Loyola, 2009. p. 91-112.

IGLÉSIAS, M. \& RODRIGUES, F. Platão. Parmênides. Rio de Janeiro/São Paulo: PUC/Loyola, 2003.

MACCABE, M. Unity in Plato's Parmenides. In: Forms and Arguments in Late Plato. Oxford: Claredon Press, 1996.

MANSFELD, J. Die Vorsokratiker, I: Milesier, Pythagoreer, Xenophanes, Heraklit, Parmenides. Stuttgart: Philipp Reclam Jun, 1986.

MORROW, G. \& DILLON, J. Proclus' Commentary on Plato's Parmenides. Princeton, N.J. : Princeton University Press, 1987.

PETERSON, S. Parmenides. In: FINE, G. The Oxford Handbook of Plato. Oxford: Oxford University Press, 2008.

ROSSVAER, V. Laborious Games: Study of Plato's Parmenides, Universitetsforlaget, 1983.

SAYRE, K. M. Parmenides' Lesson, Notre Dame, University Press, 1996

SCOLNICOV, S. Plato's Parmenides: translated with an introduction and commentary. Berkeley, University of California Press, 2003.

TURNBULL, R. G. The Parmenides and Plato's Late Ontology, Toronto, University of Toronto Press, 1998 